\title{
Strategies of German Bundesliga and English Premier League clubs for the COVID-19 crisis: the case of international broadcasting fans
}

\author{
José F. Navarro-Picado ${ }^{1}\left[\right.$ ] Eduardo Torres-Moraga ${ }^{2}$.

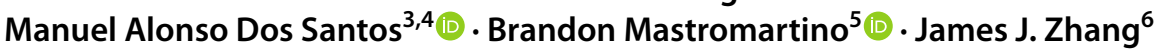

Received: 13 May 2021 / Accepted: 28 December 2021 / Published online: 13 January 2022

(c) The Author(s) 2022

\begin{abstract}
During the COVID-19 pandemic that paused sports worldwide, the German Bundesliga League (GBL) and English Premier League (EPL) took two different strategic approaches to agree with their players on returning to play. To become better informed and prepared for future crisis management, this study examines consumer responses to these opposing strategies. We also identify how perceived organizational legitimacy, trustworthiness, reliance, and justifiability have an impact on consumer multimedia consumption of the games. A sample of 503 participants responded to an online questionnaire regarding the contrasting decisions taken by the GBL and the EPL during the global health crisis. SEM with multi-group analysis was conducted to test the research hypotheses. When comparing the two selected sport leagues, the league that reached an agreement with their players experienced higher levels of perceived legitimacy while needing fewer perceptions of trustworthiness, reliance, and justifiability to obtain higher multimedia consumption intention from consumers.
\end{abstract}

Keywords Legitimacy perception · Decision justifiability · Organizational trustworthiness $\cdot$ Multimedia consumption

Manuel Alonso Dos Santos

manuelalonso@ugr.es

1 School of Business Administration, Universidad de Costa Rica, San José, Costa Rica

2 School of Economic and Business, Universidad de Chile, Santiago, Chile

3 Marketing and Market Research Department, Universidad de Granada, Granada, Spain

4 Department of Management, Faculty of Economics and Business Administration, Universidad Católica de la Santísima Concepción, Concepción, Chile

5 Department of Applied Physiology \& Sport Management, Simmons School of Education \& Human Development, Southern Methodist University, Dallas, Texas, USA

6 Department of Kinesiology, The University of Georgia, Athens, GA, USA 
JEL classification M39 marketing and advertising-Other $\cdot$ M59 personnel economics-other

\section{Introduction}

March 2020 will always be remembered as the month when sporting events, along with many other organized activities and public gatherings, were restricted or canceled worldwide to counteract the spread of COVID-19 (Majumdar and Naha 2020). Although health measures such as the shutdown of stadiums or postponing of games were to protect fans and athletes from contracting the virus (Corsini et al. 2020) and related risks (Mann et al. 2020), the sport industry has faced immense economic pressure to return to normal operations as soon as possible (Mastromartino et al. 2020; Drewes et al. 2021). During crisis periods, such as the COVID-19 era, judging what is normal and what is not is a challenge for society in general (Clark et al. 2020), especially in sport organizations (Hammerschmidt et al. 2021a, b). Among these uncertainties, reliance is an important tool for consumers to maintain an interest in institutions (Doney and Cannon 1997).

Individuals tend to be tolerant of certain changes but simultaneously expect to see an alignment of the new happenings to their relevant institutions (Ödlund 2010). For example, during the COVID-19 crisis, fans expected that sport leagues could reach salary agreements with their players in a way that to allow the team to adjust to the financial issues of the clubs while keeping the players and staff employed (Sheptak and Menaker 2020). In this context, consumers' evaluations of the legitimacy, justifiability, and trustworthiness of a league's decisions come into play. Although individual judgments on what is legitimate, justifiable, and dependable have been overlooked in the past, little is known about how these judgments adapt during crisis periods and how they interact with consumption behaviors. As these variables can potentially positively impact consumer evaluation in different contexts, they are deemed relevant for consumption intention behavior (e.g. Sen and Morwitz 1996; Niemi and Kantola 2018; Dabbous and Tarhini 2019; Ismagilova et al. 2020).

It is highly possible that during periods of crisis, perceived organizational legitimacy, trustworthiness, reliance, and the justifiability of the decisions taken by the relevant institutions would show different intensities in individuals' intentions to consume multimedia. Specifically, this study was based on the social judgment theory (SJT) (Bitektine 2011) and norm theory (NT) (Feldman et al. 2020) and in the context of the COVID-19 health crisis. It was designed to investigate whether institutions that took certain consumer-expected concrete actions would experience higher levels of organizational legitimacy while relying less on the trustworthiness, reliance, and justifiability of a decision to adopt their pathway toward multimedia consumption intention (MMCI). MMCI is deemed to be a relevant variable for professional sport organizations, especially during the current sanitary crisis. Owing to the impossibility of teams and leagues to receive fans in their properties, it is the major and, momentarily, the only exposure channel on matchdays. 
Sport broadcasts accrue the largest audience of all television shows (KnoblochWesterwick et al. 2020). With recent innovations in communications and technology (Haynes 2021), sport fans worldwide can experience live events through different paid platforms (Cobbs and Hilton 2012). This has led top-tier sport leagues to receive increased revenue through broadcasting rights (Tamir 2019). Tamir (2019) further suggests that through a personalized experience of simultaneous game-related content, watching games in the arena has become indispensable for fans to a lesser extent. Domestic broadcasting rights are experiencing a slight drop, while international telecasting deals continue to grow (Geey and Harvey 2019).

Football is the most popular sport globally, accounting for over 3.5 billion fans worldwide, while the next sport (cricket) drops to 2.5 billion fans (Das 2021). Specifically, in Latin America, football is unquestionable as the most popular sport (Sotomayor 2020), suggesting that fans in the region are considerably knowledgeable about top-tier leagues and related topics (Ridge 2017). As one of the most-watched leagues worldwide, EPL games are broadcast in every country in Latin America except Cuba (Premier League 2019). The GBL also has full coverage through free-to-air (FC Bayern 2020) or paid platforms (Bertran 2020).

Previous studies have seldom considered these variables when analyzing how the decisions made by sport leagues in a crisis can impact multimedia consumption, and no fans could access the stadiums or arenas at the time of the study (Corsini et al. 2020; Majumdar and Naha 2020). Therefore, this study focused on identifying the differential roles that perceived organizational legitimacy, trustworthiness, reliance, and the justifiability of decisions by sport leagues play to reach an agreement with players and lead to the MMCI of those leagues. Noticeably, this study considered the situational differences between the GBL and the EPL, in which the GBL could reach a salary agreement between the league and players' union, while the EPL could not.

Regarding the EPL's salary agreement, it was reported that there was a lack of interest in making any change (Roan 2020). Simultaneously, it has been argued that although the EPL did not reach an agreement, many other industries did not reach labor agreements. However, unlike other industries (Hammerschmidt et al. 2021a, b), due to media exposure and well-known wealth, the EPL received extensive media attention during this period (Kennedy and Kennedy 2021).

The only information that fans had readily available was through the media, especially for fans outside the UK, such as those in Latin America. Therefore, to the fan's best knowledge, the actual difference between what was done by the EPL and the GBL was that the first one did not reach a salary agreement while the second one did. Specifically, and according to the news, the EPL showed no further interest in reaching an agreement, which was indicated in multiple media sources such as in the following excerpt:

"In a joint statement, the Premier League, EFL, PFA, and League Managers' Association said they had a 'constructive meeting' on Wednesday regarding the challenges facing the game... No decisions were taken with discussions set to continue in the next 48 hours with a focus on several high-profile mat- 
ters, including player wages and the resumption of the 2019-20 season." BBC Sports, April 2020

"...footballers and clubs are on the receiving end of flak for the delays when it comes to voluntary salary reductions to help their fellow non-playing colleagues..." Goal, April 2020

"The British Health Secretary, Matt Hancock, singled out Premier League footballers in a press conference on Thursday, calling on them to take pay cuts to help the economy during the coronavirus crisis...However, there are clubs like Tottenham Hotspur, who have put non-playing staff on furlough without reducing the wages of their players." Marca, April 2020

\section{Theoretical background}

SJT suggests that individuals use a weighting process when evaluating an object (Hoffmann et al. 2019), employing an attitudinal anchor to guide their categorization (Kyle et al. 2004), and allocating the object toward a latitude of acceptance or rejection (Rhine and Severance 1970). Accordingly, individuals use legitimacy as a relevant classification variable when judging an object (Bitektine 2011). Thus, the credibility of the source (Rhine and Severance 1970), individuals' experience (Brehmer and Brehmer 1988), and social standards (Kyle et al. 2004) play a key role in the assessment made. Within this framework, an assumption made is that individuals have a lack of access to "real" information (Zacharakis and Meyer 1998), are influenced by "majority group" opinions (Van Swol et al. 2018) and have more inflexible positions depending on their ego involvement toward the focal object (Kyle et al. 2004).

Although the evaluation is performed through the SJT lens every time the object arises, the evaluation process is lasting and stable over time (Mao et al. 2018). Regardless of the circumstances, individuals expect established organizations to behave according to their legitimacy as a base element for any decisions. This is especially the case under difficult circumstances, such as the COVID-19 pandemic (Kraus et al. 2020). However, NT is a stimulus-centered judgment, where an individual faces a situation; regardless of past events, they need to allocate the object into a normality categorization (Kahneman and Miller 1986). When evaluating what is normal and what is not, individuals are more affected by abnormal decisions, arising sentiments of regret (Feldman et al. 2020), and contextual situations (Emami et al. 2021) have a relevant impact on the evaluation of whether action or inaction should be considered a more normal decision (Temerak and El-Manstrly 2019). According to Kahneman and Miller (1986), exceptional or out-of-the-routine events are those that seem to have highly available alternatives. Conversely, regular or routine events are sometimes easy representations that evoke little surprise in the judge's mind. It has been suggested that these situational cues produce common social expectations (Blay et al. 2018), thus guiding public opinion. Blay et al. (2018) argue that individuals cannot separate themselves from their social contexts, creating pressure toward accepting certain social norms and guiding individuals to justify any decision taken to align with these circumstances. 
Football fandom, local leagues and clubs, and top-tier football leagues are part of Latin American culture (Sotomayor 2020). People across the continent have access to live or delayed broadcasting of the entire GBL and EPL season games among other premium football leagues (Premier League 2019; Bertran 2020; FC Bayern 2020), fostering a massive, knowledgeable fan base who regularly gather with friends and family to watch games (Ridge 2017).

Noticeably, top-tier professional football leagues, including GBL and EPL, enjoy a loyal base globally and specifically in the Latin American region (Das 2021). Consumers constantly place football media content on top of their broadcasting program`s choice list (Knobloch-Westerwick et al. 2020). Certainly, the high media attention can make the top leagues vulnerable to positive, negative, or unwanted media exposures (Kennedy and Kennedy 2021).

During crisis conditions, organizations regularly show poor efficiency, cooperation (Ödlund, 2010), and coopetition behaviors (Hammerschmidt et al. 2020) while experiencing difficulties in their communication processes (Palttala and Vos 2011). This is why individuals tend to better evaluate institutions that change their normality and proceed with action toward adaptation (Feldman 2020). For example, during the health crises caused by COVID-19, individuals expected organizations to behave according to what was needed in that specific environment and time, such as financial agreements to preserve jobs and protect employees. Within the specific sports context in which we conducted the study, GBL clarified that their top priority was job retention and employee protection (Drewes et al. 2021), indirectly avoiding clubs from entering into higher financial risks (Horky 2021). Simultaneously, EPL was unclear on any action or intention at the moment (Kennedy and Kennedy 2021). The SJT and NT theories help us understand the evaluations made by individuals toward the decisions taken by organizations.

\subsection{Perceived organizational legitimacy}

Drawing on SJT, legitimacy perception is considered as a baseline foundation that would affect any other upgraded categorization (Bitektine 2011) and is important for institutional survival and eventual thriving (Hutchins et al. 2019). Regarding NT, theorists suggest that moral virtues such as benevolence (trustworthiness) and reliance help facilitate the creation and development of social norms (Blay et al. 2018). As few studies have specifically examined this topic area, little is known about how perceived organizational legitimacy can help or benefit an organization's subsequent trustworthiness and reliance. Individuals tend to evade regret by adopting more justifiable options (Inman and Zeelenberg 2002), thereby avoiding dubious decisions (van de Calseyde et al. 2018). Simultaneously, people feel a higher need for stability (i.e., sticking to what they have) when the decision-maker is themselves. However, people tend to recommend switching behavior when the object of analysis is someone else (Saine et al. 2018).

When evaluating an institution, the higher the perceived organizational legitimacy of the organization, the higher its trustworthiness, and the easier it is to justify any decision taken by the same organization (Fan and Wu 2019). Within sports, 
perceived organizational legitimacy can be expected to impact both sponsorship garnering (Navarro-Picado 2019) and fans' consumption intentions (Navarro-Picado et al. 2020). This relationship needs further understanding, as perceived organizational legitimacy could act through trustworthiness and the justifiability of a specific decision taken. These illustrations and discussions lead to the following two hypotheses:

$\mathbf{H}_{\mathbf{1}}$ Higher levels of perceived organizational legitimacy would increase the leagues' trustworthiness.

$\mathbf{H}_{\mathbf{2}}$ Higher levels of perceived organizational legitimacy would increase the justifiability of decisions.

\subsection{Trustworthiness during a crisis}

Despite being an essential variable for decision-making (Pena-Marin and Wu 2019), trustworthiness has rarely been studied in the context of sport management. Trustworthiness is a multidimensional construct composed of ability, benevolence, and integrity (Mayer and Davis 1999). Ability is considered the most tangible dimension (Jacobsen and Andersen 2015), representing the intellect and interpersonal skills needed for successful performance (Maxwell and Lévesque 2014). Benevolence accounts for the perception that the supplier would place the consumer's benefit before its own interests (Caldwell and Hayes 2007), becoming the most emotional dimension of the construct (Moloney 2005). The last dimension is integrity, which is more related to ethical requirements (Caldwell and Hayes 2007) and the perceived expectancy of organizations keeping their words and fair treatments (Hosmer 1995).

Reliance is an important variable that can strengthen an organization's relationships with stakeholders (Bejou et al. 1998; Crane 2020). It is built from a cognitive process (Morrow et al. 2004; Ozdemir et al. 2020) that involves the experience of individuals with the organization (Lovell 2009) and the reputation of the organization as to whether it is honorable (Flores and Solomon 1998; Bellucci and Park 2020). Trustworthiness captures the tendency or propensity to believe in something (Sekhon et al. 2014) and is considered a common antecedent of reliance itself (Caldwell and Clapham 2003). Consequently, the following hypothesis is formulated:

$\mathbf{H}_{\mathbf{3}}$ Higher levels of trustworthiness would increase the reliance on a sport league.

\subsection{Level of reliance in sport leagues}

Reliance is a relevant construct to consider during difficult time periods (Rousseau et al. 1998). People tend to believe that the organizations they rely on would solve problems in the best way for their customers (Martínez et al. 2020). Specifically, within a sports context, reliance serves as an enhancer of fans' consumption behaviors (Kim et al. 2011). To better understand the relevance of reliance in the context of the COVID-19 pandemic, it is valuable to follow Rousseau et al.'s (1998) 
definition. It suggests that reliance is a "psychological state comprising the intention to accept vulnerability based upon positive expectations of the intentions or behavior of another" (p. 395). Apparently, this explanation would imply accepting vulnerability in a moment in which people are already vulnerable due to the pandemic. The main difference between these terms is that trustworthiness is related to the reputation managed by the trustee (Sekhon et al. 2014), while reliance is based on subjective perception, which acts as an individual lens for each person (Caldwell and Clapham 2003).

The GBL and the EPL are visible due to historical successes and attract high consumption levels through multimedia (Ajadi et al. 2020). As with any other sport institution, they are expected to rely on fans (Garbarino and Johnson 1999) and thus benefit from higher levels of fan consumption intentions (Cho et al. 2020) under the assumption that any related decision can be justified and would not substantially hamper the existent level of reliance (Alonso 2016). These discussions lead to the following hypotheses:

$\mathbf{H}_{\mathbf{4}}$ Higher levels of reliance would positively impact the multimedia consumption intention.

$\mathbf{H}_{\mathbf{5}}$ Higher levels of reliance would positively impact the justifiability of the decision.

\subsection{Justifying unconventional decisions}

According to NT, individuals tend to establish an anchor toward what is considered normal to themselves, making it easier to justify sticking to some actions instead of switching to alternatives (Kahneman and Miller 1986). NT originally suggested that the status quo is generally considered "more normal" than an alternative situation. However, recent research findings indicate that this could be reversed in cases where past behavior, situational expectations, and social norms advise a switching decision as more normal than a staying decision (Feldman 2020). When evaluating what is normal and what is not, individuals are more affected by abnormal decisions, arising sentiments of regret (Feldman et al. 2020). Nonetheless, contextual situations have a relevant impact on the evaluation of whether action or inaction should be considered a comparatively more normal decision (Temerak and El-Manstrly 2019). If individuals tend to favor highly justifiable alternatives, it can be argued that individuals would consume the multimedia of sport organizations perceived to have made justifiable decisions. Accordingly, the following hypothesis was developed:

$\mathbf{H}_{\mathbf{6}}$ Higher levels of the justifiability of the decision would increase the intention to consume multimedia.

Globalization has impacted almost every person on the planet, which is especially highlighted in times of crisis (Palttala and Vos 2011). Individuals and societies struggle during these scenarios, while different public and private organizations 
compete for limited resources in an environment that demands rapid learning and actions (Ödlund 2010). During crisis conditions, organizations regularly show poor efficiency and cooperation behaviors (Ödlund 2010) and difficulties in communication (Palttala and Vos 2011). This is why individuals tend to better evaluate institutions that, in these circumstances, show determination toward adaptation (Feldman 2020). Reasonably, in a situation such as the public health crisis derived from the COVID-19 pandemic, individuals would tend to justify some decisions that would normally be considered abnormal and consequently allocate higher value to those organizations that attempt to change rather than remain still. With the justifiability of the decision to be a comparison variable (van de Calseyde et al. 2018), a contrast between the status quo and an adaptation decision arises as a logical test.

In the context of a pandemic, it can be expected that adaptable sport leagues are likely to make some arrangements to prevail during the crisis period. Even if the organization's stability has not been jeopardized, social evaluation could positively or negatively impact a sport league depending on the decisions taken (Verbruggen and Van Emmerik 2020). Under these conditions, it can be argued that professional sport leagues who reach a salary agreement during the crisis period would experience an increase in their perceived organizational legitimacy, which would positively impact both the level of perceived trustworthiness and the justifiability of the decision (Fan and Wu 2019). Assuming a domino effect, we expect that, in the same context, lower levels of trustworthiness will be needed to rely on organizations that reach a salary agreement. Similarly, individuals would need lower levels of reliance to justify the decision

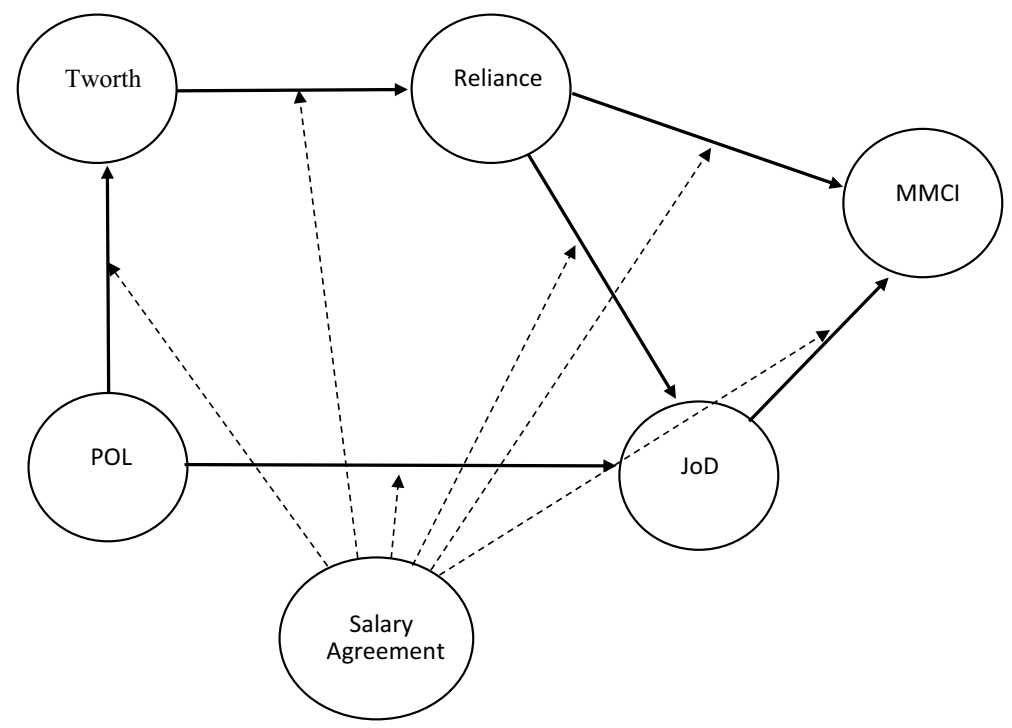

Fig. 1 Hypothetical Research Model Depicting the Relationships among Perceived Organizational Legitimacy, Trustworthiness, Reliance, Justifiability of Decision and Multimedia Consumption Intention, moderated by a (no) salary agreement during the COVID-19 crisis. Note: dashed line (---) crosses hypothesis affected by moderation. Tworth $=$ Trustworthiness, POL $=$ Perceived Organizational Legitimacy, $\mathrm{JoD}=$ Justifiability of Decision, $\mathrm{MMCI}=$ Multimedia Consumption Intention 
taken and show higher levels of multimedia consumption intention (Sen and Morwitz 1996) while needing less justifiability to increase their multimedia consumption intention. The following hypotheses were formulated (Fig. 1):

$\mathbf{H}_{\mathbf{7 a}}$ Sport leagues that reached a salary agreement would experience a stronger relationship between perceived organizational legitimacy and trustworthiness.

$\mathbf{H}_{\mathbf{7 b}}$ Those sport leagues that reached a salary agreement would experience a stronger relationship between perceived organizational legitimacy and justifiability of decision.

$\mathbf{H}_{7 c}$ Those sport leagues that reached a salary agreement would experience a weaker relationship between perceived trustworthiness and reliance.

$\mathbf{H}_{\text {7d }}$ Those sport leagues that reached a salary agreement would experience a weaker relationship between reliance and justifiability of decision.

$\mathbf{H}_{\mathbf{7 e}}$ Those sport leagues that reached a salary agreement would experience a weaker relationship between reliance and MMCI.

$\mathbf{H}_{\mathbf{7 f}}$ Those sport leagues that reached a salary agreement would experience a weaker relationship between justifiability of decision and MMCI.

\section{Method}

\subsection{Participants}

Respondents were recruited through either a Qualtrics mailing list or MTurk for Latin American football consumers between April and May 2020. All research participants were over 18 years old and were confirmed to have a fundamental knowledge of football and familiarity with top-tier professional football leagues. After eliminating incomplete questionnaires, 503 valid responses (13 Qualtrics, 490 MTurk) were formally collected. The response ratio was 3.2\% in the case of the Qualtrics mailing list (13/407), while MTurk was 58.7\% (490/835), with an average age of $30.34(\mathrm{SD}=10.83)$. Of the participants, 329 were men, and 174 were women. Table 1 presents the descriptive statistics of the respondents.

For top-tier professional football leagues, broadcasting and media income represent up to $66 \%$ of their income, whereas live event spectator revenue (e.g., ticketing

Table 1 Descriptive statistics of the sample

\begin{tabular}{lccll}
\hline Gender/age & $18-25$ & $26-35$ & $36-45$ & 46 -older \\
\hline Women & 73 & 55 & 31 & 15 \\
Men & 134 & 115 & 49 & 31 \\
\hline
\end{tabular}


and concessions) is lower. This is the case for both GBL (Horky 2021) and EPL (Kennedy and Kennedy 2021). According to Horky (2021) and Kennedy and Kennedy (2021), income share due to matchday spectators barely represents $13 \%$ for football, while other sports within Germany, such as ice hockey (32\%), are more dependent on spectator attendance at the game events. Therefore, we chose to conduct the study in a Latin American setting based on the following three considerations: (a) high exposure to and involvement of Latin American sport fans in football; (b) their general highlevel knowledge of football and familiarity with top-tier professional football leagues in the world (Giulianotti and Robertson 2012); (c) strong intention of investigators of this study to mitigate any localness effects associated with the EPL and GBL (Mandler et al. 2020).

\subsection{Measurement}

A questionnaire was developed that contained the following sections: (a) an informed consent, which requested participants to confirm their voluntary participation and that they were above 16 years old and had some knowledge of top-tier football; (b) a little contextualization on COVID-19; its impact on sports and approach differences between the EPL and GBL in these circumstances; (c) the core questionnaire. All measures in this study were adopted or adapted from those developed in previous studies. MMCI was assessed through a three-item scale based on the research of Kim et al. (2011), which includes questions such as "I will watch or listen to the (Bundesliga/Premier League) games through the media (e.g., TV, Internet, Radio, etc.)." Justifiability of Decision (JoD) is also a three-item scale, based on Inman and Zeelenberg's (2002) scale, with items such as "How justifiable is the decision to (not) reach a salary agreement?" The scale for assessing reliance is based on the research of Kim et al. (2020) and includes items such as "I would be comfortable giving the (Bundesliga/PremierLeague) total responsibility of the activities.” Trustworthiness was assessed through a 17-item scale based on the research of Mayer and Davis (1999), including items such as "The (Bundesliga/Premier League) is capable of performing its job.” Perceived organizational legitimacy was assessed based on Fidan and Balci's (2018) scale, which included items such as "The (Bundesliga/ Premier League) is compatible with the values of the general public." For sample description purposes, a section on sociodemographic background variables was included in the survey form, asking for the age and sex of the participants.

As the aforementioned scales adapted for this study were originally published in English language scholarly journals, items of each scale were translated into Spanish. Double translations were made to ensure linguistic validity (Chapman and Carter 1979). A panel of five experts with a specialized background in professional sport league management theories and practices were invited to evaluate content validity (Crocker and Algina 1986). The panel members were asked to examine each item's relevance, representativeness, and clarity for a specific concept. Adopting a standard of $80 \%$ agreement among the panel members, all items were retained after revisions and modifications were made to improve linguistic expressions for a few 
items. All the items were phrased on a Likert 7-point scale, ranging from $1=$ strong disagreement to $7=$ strong agreement. The items were arranged in a random order within each of the sections, and Table 2 shows the means and standard deviations for all items.

\subsection{Procedures}

We aimed to assess the moderating effect of the perceived differences between what was done by the Bundesliga and the Premier League during the health crisis. A little contextualization was articulated and presented to all participants at the beginning of the survey. This was aligned with the strong speculations by major media outlets regarding the lack of interest in making a change on the part of the EPL (Roan 2020) and was also consistent with the scientific literature with reference to the undeserving efforts made by this league (Kennedy and Kennedy 2021). Textually, this introduction said, "Given the current global contingency, some sports leagues, unlike others, have taken important measures to face these difficult times. For example, the German Bundesliga has actively collaborated so that all its clubs reach salary agreements and maintain the jobs of the players and the entire staff. Nevertheless, little effort has been made to achieve these goals in the EPLeague."

Responses to the questionnaire were obtained electronically through Qualtrics mailing distribution; individuals received an email invitation to participate and a link to the survey or MTurk for Latin America through Amazon's MTurk platform. After individuals agreed to participate in the study, they were randomly assigned to respond to the questionnaire regarding only one league, Bundesliga (261 respondents) or Premier League (242 respondents). As the study was conducted in a different sociocultural, linguistic, and sports setting than the original scales in the questionnaire, it was deemed necessary to reexamine the validity and reliability of the measures in the questionnaire. An exploratory factor analysis (EFA) was performed using the SPSS program, followed by a confirmatory factor analysis (CFA) by executing the AMOS program (Anderson and Gerbing 1988). Structural equation model (SEM) analyses were conducted to examine the research hypotheses.

\section{Results}

When conducting EFA, a factor loading threshold was set to 0.50 or higher without double-loading, while a criterion of 0.70 was set for a Cronbach's alpha coefficient (Nunnally 1994). All measures satisfied these criteria; subsequently, it was deemed appropriate to proceed with conducting a CFA. The model fit indexes included RMSEA $=0.064, \mathrm{CFI}=0.908, \mathrm{IFI}=0.909, \mathrm{TLI}=0.899$, and normed chi-square of 3.05 , indicating that the data fit the measurement model well. All items were preserved because of their high levels of convergence and $\mathrm{R}^{2}$. To avoid any possible underestimation from the Cronbach's alpha (Smith 1974), a composite reliability test was conducted (Jöreskog 1971), setting the threshold to the recommended 0.65 


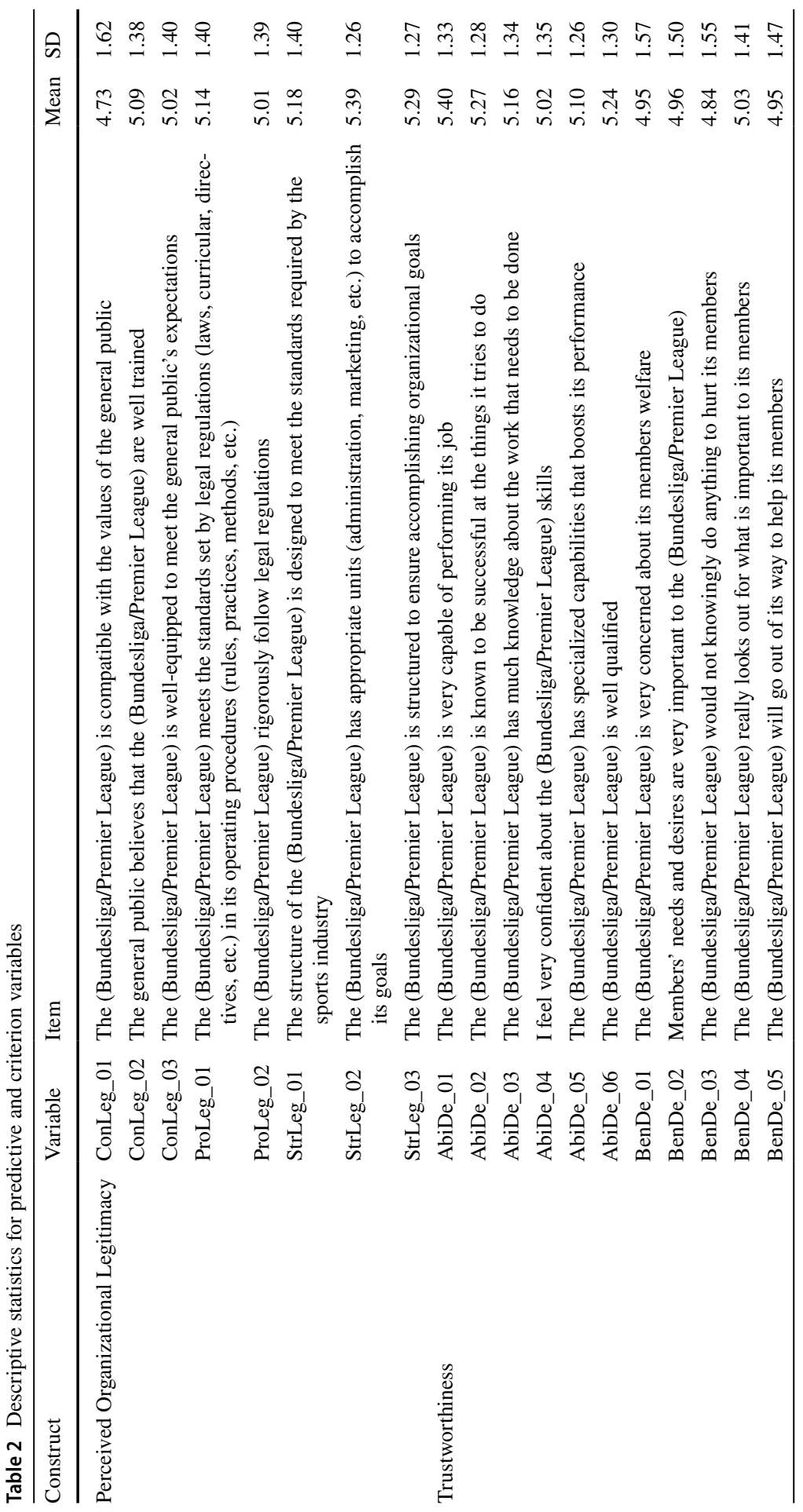




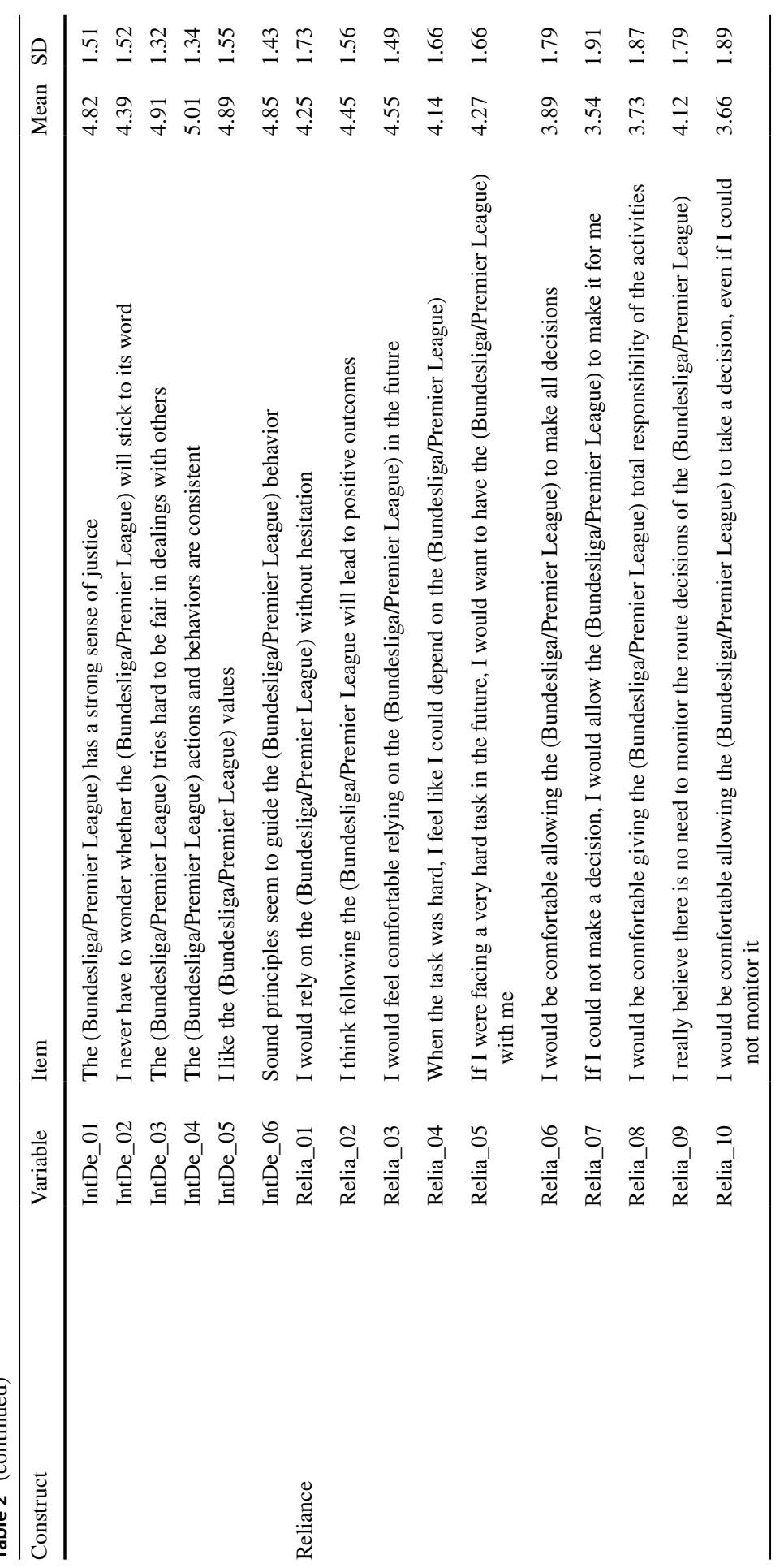




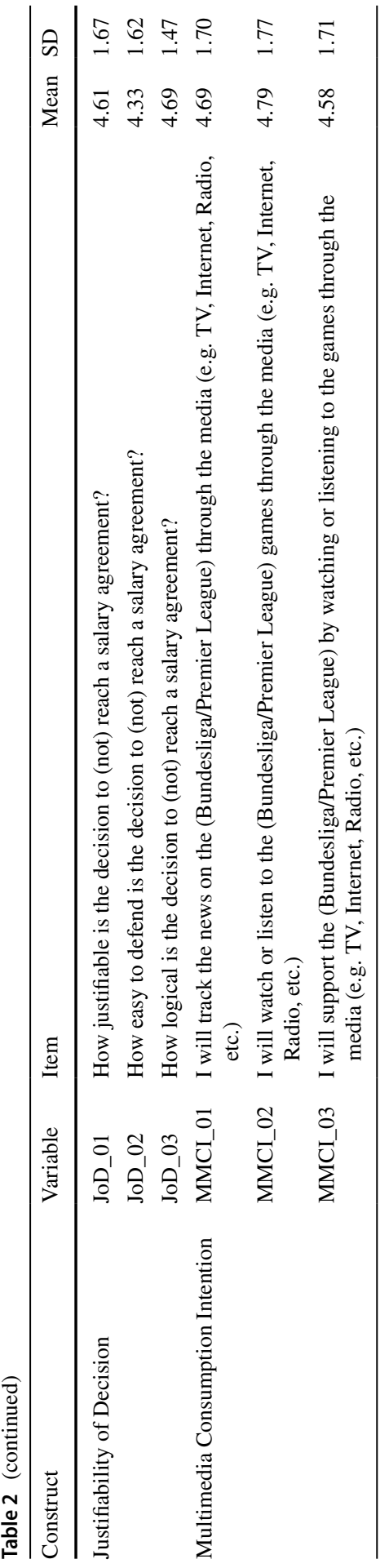


(Steenkamp and Geyskens 2006). Adopting the threshold of 0.50, convergent validity was confirmed by calculating average variance extracted (AVE) coefficients (Fornell and Larcker 1981). Finally, discriminant validity was tested by verifying that number 1 was not included in the confidence interval of any correlation pair (Anderson and Gerbing 1988). All these findings suggest adequate psychometric properties of the measurement scales, and their respective figures are shown in Table 3 regarding the CFA, composite reliability, and convergent validity. Table 4 refers to the correlational analysis and discriminant validity.

The SEM analyses revealed that satisfactory values support model fit to the data, as the model achieves an RMSEA of 0.071 , CFI of 0.883 , IFI of 0.883 , TLI of 0.874 , and normed chi-square of 3.54. The findings indicate that perceived organizational legitimacy had a positive effect on trustworthiness $(.911, p<.01)$ and justifiability of decision $(.683, p<.01)$, supporting $\mathrm{H}_{1}$ and $\mathrm{H}_{2}$. Trustworthiness positively impacted reliance $(.620, p<.01)$, while reliance had a positive effect on justifiability of decision $(.170, p<.01)$ and MMCI $(.624, p<.01)$, supporting $\mathrm{H}_{3}, \mathrm{H}_{4}$, and $\mathrm{H}_{5}$. At this step of the study, the relationship between the justifiability of decision and MMCI was not found to be statistically significant $(p>.51)$ (Fig. 2).

During the data collection process, participants were randomly assigned to evaluate the decision of either the Bundesliga (reaching an agreement) or the Premier League (no agreement). Therefore, and in line with NT, the Bundesliga took action while the Premier League stayed in its status quo. A multi-sample analysis was performed to test the moderation effect, which corresponded to $\mathrm{H}_{7 \mathrm{a}}$ through $\mathrm{H}_{7 \mathrm{f}}$. A total of 261 individuals were assigned to Bundesliga, while 242 were allocated to the Premier League. A CFA invariance test was performed prior to the multi-sample analysis (Silva et al. 2019). It has been recommended that three test levels should be assessed: (a) configural invariance (good model fit in the multi-group sample); (b) metric invariance (unconstrained vs. structural weights CFI difference test below .01 ); (c) structural invariance (unconstrained vs. structural weight chi-square insignificance differences) (Cheung and Rensvold 2009). Configural invariance was supported with coefficients of $\mathrm{RMSEA}=0.049, \mathrm{CFI}=0.887, \mathrm{IFI}=0.888, \mathrm{TLI}=0.875$, and normed chi-square $=2.20$. Metric invariance was satisfactory, with a CFI difference of 0.000 (unconstrained $0.887-0.887$ measurement). The chi-square difference test was unsatisfactory. Nonetheless, we assumed the invariance as two out of three tests were accomplished and sticking to the suggestion made by Cheung and Rensvold (2009) regarding the lack of practicality and restrictiveness of the chisquare difference test, which was also recently backed by other researchers (French and Finch 2006). A multi-sample analysis allowed us to recognize the disparities between the coefficients of the two models by generating a single solution for each of them (Table 5).

As shown in Table 5, there were no significant differences between perceived organizational legitimacy and trustworthiness. However, there was a strong significance in the differences between perceived organizational legitimacy and justifiability of decision, with a higher coefficient in the agreement (Bundesliga) case. There was also strong significance when analyzing the differences between trustworthiness and reliance, and from reliance to the justifiability of decision, showing higher coefficients for the no-agreement (Premier League) group. The 
Table 3 Confirmatory factor analysis, composite reliability, and convergent validity

\begin{tabular}{|c|c|c|c|c|c|c|c|}
\hline Item & $\begin{array}{l}\text { Standard- } \\
\text { ize solu- } \\
\text { tion }\end{array}$ & t-value & Item $\mathrm{R}^{2}$ & Factor & Cronbach's Alpha & $\begin{array}{l}\text { Composite } \\
\text { Reliability }\end{array}$ & AVE \\
\hline ConLeg_01 & 0.756 & 65.522 & 0.547 & \multirow{3}{*}{$\begin{array}{c}\text { Consequential } \\
\text { legitimacy }\end{array}$} & \multirow[t]{3}{*}{0.832} & \multirow[t]{3}{*}{0.841} & \multirow[t]{3}{*}{0.638} \\
\hline ConLeg_02 & 0.830 & 82.675 & 0.711 & & & & \\
\hline ConLeg_03 & 0.809 & 80.571 & 0.661 & & & & \\
\hline ProLeg_01 & 0.841 & 82.063 & 0.715 & \multirow{2}{*}{$\begin{array}{l}\text { Procedural legiti- } \\
\text { macy }\end{array}$} & \multirow[t]{2}{*}{0.844} & \multirow[t]{2}{*}{0.844} & \multirow[t]{2}{*}{0.729} \\
\hline ProLeg_02 & 0.867 & 80.894 & 0.744 & & & & \\
\hline StrLeg_01 & 0.830 & 82.887 & 0.689 & \multirow[t]{3}{*}{ Structural legitimacy } & \multirow[t]{3}{*}{0.849} & \multirow[t]{3}{*}{0.849} & \multirow[t]{3}{*}{0.653} \\
\hline StrLeg_02 & 0.770 & 95.994 & 0.593 & & & & \\
\hline StrLeg_03 & 0.823 & 93.186 & 0.679 & & & & \\
\hline AbiDe_01 & 0.800 & 91.350 & 0.641 & \multirow[t]{6}{*}{ Ability } & \multirow[t]{6}{*}{0.891} & \multirow[t]{6}{*}{0.890} & \multirow[t]{6}{*}{0.574} \\
\hline AbiDe_02 & 0.728 & 92.528 & 0.527 & & & & \\
\hline AbiDe_03 & 0.711 & 86.545 & 0.504 & & & & \\
\hline AbiDe_04 & 0.797 & 83.163 & 0.635 & & & & \\
\hline AbiDe_05 & 0.726 & 90.519 & 0.529 & & & & \\
\hline AbiDe_06 & 0.780 & 90.317 & 0.608 & & & & \\
\hline BenDe_01 & 0.872 & 70.534 & 0.758 & \multirow[t]{5}{*}{ Benevolence } & \multirow[t]{5}{*}{0.919} & \multirow[t]{5}{*}{0.922} & \multirow[t]{5}{*}{0.703} \\
\hline BenDe_02 & 0.878 & 74.108 & 0.772 & & & & \\
\hline BenDe_03 & 0.708 & 70.176 & 0.502 & & & & \\
\hline BenDe_04 & 0.864 & 79.972 & 0.745 & & & & \\
\hline BenDe_05 & 0.857 & 75.693 & 0.736 & & & & \\
\hline IntDe_01 & 0.848 & 71.629 & 0.721 & \multirow[t]{6}{*}{ Integrity } & \multirow[t]{6}{*}{0.890} & \multirow[t]{6}{*}{0.894} & \multirow[t]{6}{*}{0.588} \\
\hline IntDe_02 & 0.577 & 64.967 & 0.334 & & & & \\
\hline IntDe_03 & 0.698 & 83.442 & 0.491 & & & & \\
\hline IntDe_04 & 0.785 & 83.978 & 0.616 & & & & \\
\hline IntDe_05 & 0.820 & 70.686 & 0.669 & & & & \\
\hline IntDe_06 & 0.836 & 76.273 & 0.697 & & & & \\
\hline Relia_01 & 0.782 & 55.144 & 0.611 & Reliance & 0.935 & 0.936 & 0.599 \\
\hline Relia_02 & 0.570 & 64.104 & 0.324 & & & & \\
\hline Relia_03 & 0.706 & 68.404 & 0.498 & & & & \\
\hline Relia_04 & 0.812 & 55.823 & 0.657 & & & & \\
\hline Relia_05 & 0.761 & 57.128 & 0.579 & & & & \\
\hline Relia_06 & 0.844 & 48.800 & 0.713 & & & & \\
\hline Relia_07 & 0.872 & 41.510 & 0.762 & & & & \\
\hline Relia_08 & 0.888 & 44.700 & 0.790 & & & & \\
\hline Relia_09 & 0.651 & 51.536 & 0.425 & & & & \\
\hline Relia_10 & 0.797 & 43.418 & 0.635 & & & & \\
\hline JoD_01 & 0.911 & 62.089 & 0.831 & Justifiability of & 0.879 & 0.879 & 0.709 \\
\hline JoD_02 & 0.767 & 59.880 & 0.588 & decision & & & \\
\hline JoD_03 & 0.842 & 71.459 & 0.710 & & & & \\
\hline MMCI_01 & 0.816 & 62.017 & 0.665 & Multimedia con- & 0.897 & 0.898 & 0.746 \\
\hline MMCI_02 & 0.895 & 60.705 & 0.800 & sumption intention & & & \\
\hline MMCI_03 & 0.878 & 60.176 & 0.772 & & & & \\
\hline
\end{tabular}


Table 3 (continued)

All t-values significant at .01 level

ConLeg consequential legitimacy, ProLeg procedural legitimacy, StruLeg structural legitimacy, AbiDe ability (trustworthiness), BenDe benevolence (trustworthiness), IntDe integrity (trustworthiness), Relia reliance, $J o D$ justifiability of decision, $M M C I$ multimedia consumption intention

reliance on the MMCI string appears to be insignificant, whereas the string of justifiability of decision to MMCI showed a trend of significance, with a higher coefficient for the no-agreement (Premier League) group. These findings revealed that in the context of the COVID-19 crisis, higher levels of perceived organizational legitimacy were allocated to leagues that reached an agreement and therefore increased the justifiability of this decision.

Additionally, for cases in which an agreement was reached, lower levels of trustworthiness were needed to rely on that league. Simultaneously, lower levels of reliance were required to manifest a multimedia consumption intention. Finally, less justifiability was needed from decisions taken by sport leagues who reached an agreement to have fans consuming multimedia.

\section{Discussion}

Drawing on the social judgment theory and norm theory, this study developed a model to investigate whether fans' judgment toward decisions made by sport leagues is aligned with theoretical expectations. Our main goal was to distinguish the evaluation differences made by fans concerning the efforts made by the sport leagues to reach an agreement versus maintaining the status quo. This was done during the global health crisis of COVID-19 and examined how this could impact the multimedia consumption intention of those leagues.

Multimedia consumption is deemed a relevant variable for top-tier leagues as broadcasting represents up to $66 \%$ of the leagues' budget (Horky 2021), especially during the lockdown period when fans are not allowed to access the arenas physically (Corsini et al. 2020; Majumdar and Naha 2020). However, fans who were directly impacted by the shutdown may experience a localness bias during that period (Mandler et al. 2020). Overall, the Latin American region has a considerably knowledgeable (Ridge 2017) and loyal fan base (Sotomayor 2020) that consumes excessive multimedia football content, particularly because of local lockdown policies caused by the pandemic crisis.

Aligned with the social judgment theory, our findings suggest that higher levels of perceived organizational legitimacy derive higher levels of trustworthiness and justifications of decisions. Therefore, legitimacy once again appears as a relevant input for organizational success, as our findings suggest that it is easier for individuals to depend (rely) on and justify decisions taken by organizations that enjoy higher levels of perceived legitimacy.

However, and aligned with recent findings of the norm theory, individuals seem to appreciate that GBL reached a downgrade salary agreement-what 
Table 4 Correlational analysis anddiscriminant validity

\begin{tabular}{|c|c|c|c|c|}
\hline \multirow{2}{*}{$\begin{array}{l}\text { Pair of constructs } \\
\text { Consequential Leg. } \leftrightarrow \text { Procedural Leg. }\end{array}$} & \multirow{2}{*}{$\begin{array}{l}\text { Correlation } \\
0.772\end{array}$} & \multirow{2}{*}{$\begin{array}{l}\text { SEE } \\
0.038\end{array}$} & \multicolumn{2}{|c|}{$\begin{array}{l}\text { Confidence } \\
\text { interval }\end{array}$} \\
\hline & & & 0.701 & 0.828 \\
\hline Consequential Leg. $\leftrightarrow$ Structural Leg. & 0.797 & 0.040 & 0.716 & 0.856 \\
\hline Consequential Leg. $\leftrightarrow$ Ability & 0.854 & 0.027 & 0.800 & 0.887 \\
\hline Consequential Leg. $\leftrightarrow$ Benevolence & 0.724 & 0.037 & 0.652 & 0.783 \\
\hline Consequential Leg. $\leftrightarrow$ Integrity & 0.762 & 0.033 & 0.706 & 0.817 \\
\hline Consequential Leg. $\leftrightarrow$ Reliance & 0.462 & 0.046 & 0.378 & 0.528 \\
\hline Consequential Leg. $\leftrightarrow$ Justifiability of Dec. & 0.712 & 0.038 & 0.636 & 0.770 \\
\hline Consequential Leg. $\leftrightarrow$ MMCI & 0.457 & 0.050 & 0.370 & 0.538 \\
\hline Procedural Leg. $\leftrightarrow$ Structural Leg. & 0.782 & 0.043 & 0.699 & 0.842 \\
\hline Procedural Leg. $\leftrightarrow$ Ability & 0.757 & 0.041 & 0.689 & 0.821 \\
\hline Procedural Leg. $\leftrightarrow$ Benevolence & 0.712 & 0.036 & 0.659 & 0.777 \\
\hline Procedural Leg. $\leftrightarrow$ Integrity & 0.740 & 0.033 & 0.682 & 0.794 \\
\hline Procedural Leg. $\leftrightarrow$ Reliance & 0.390 & 0.044 & 0.309 & 0.457 \\
\hline Procedural Leg. $\leftrightarrow$ Justifiability of Dec. & 0.661 & 0.038 & 0.599 & 0.724 \\
\hline Procedural Leg. $\leftrightarrow$ MMCI & 0.334 & 0.047 & 0.255 & 0.416 \\
\hline Structural Leg. $\leftrightarrow$ Ability & 0.931 & 0.021 & 0.894 & 0.963 \\
\hline Structural Leg. $\leftrightarrow$ Benevolence & 0.694 & 0.042 & 0.627 & 0.756 \\
\hline Structural Leg. $\leftrightarrow$ Integrity & 0.698 & 0.036 & 0.635 & 0.749 \\
\hline Structural Leg. $\leftrightarrow$ Reliance & 0.310 & 0.046 & 0.229 & 0.383 \\
\hline Structural Leg. $\leftrightarrow$ Justifiability of Dec. & 0.529 & 0.045 & 0.447 & 0.599 \\
\hline Structural Leg. $\leftrightarrow$ MMCI & 0.406 & 0.046 & 0.334 & 0.486 \\
\hline Ability $\leftrightarrow$ Benevolence & 0.748 & 0.037 & 0.677 & 0.806 \\
\hline Ability $\leftrightarrow$ Integrity & 0.787 & 0.034 & 0.728 & 0.835 \\
\hline Ability $\leftrightarrow$ Reliance & 0.451 & 0.042 & 0.374 & 0.514 \\
\hline Ability $\leftrightarrow$ Justifiability of Dec. & 0.587 & 0.043 & 0.505 & 0.651 \\
\hline Ability $\leftrightarrow$ MMCI & 0.543 & 0.039 & 0.478 & 0.609 \\
\hline Benevolence $\leftrightarrow$ Integrity & 0.930 & 0.014 & 0.902 & 0.949 \\
\hline Benevolence $\leftrightarrow$ Reliance & 0.556 & 0.040 & 0.490 & 0.621 \\
\hline Benevolence $\leftrightarrow$ Justifiability of Dec. & 0.744 & 0.031 & 0.691 & 0.793 \\
\hline Benevolence $\leftrightarrow$ MMCI & 0.390 & 0.052 & 0.301 & 0.472 \\
\hline Integrity $\leftrightarrow$ Reliance & 0.671 & 0.038 & 0.603 & 0.728 \\
\hline Integrity $\leftrightarrow$ Justifiability of Dec. & 0.780 & 0.029 & 0.728 & 0.821 \\
\hline Integrity $\leftrightarrow$ MMCI & 0.495 & 0.047 & 0.418 & 0.570 \\
\hline Reliance $\leftrightarrow$ Justifiability of Dec. & 0.520 & 0.045 & 0.438 & 0.587 \\
\hline Reliance $\leftrightarrow$ MMCI & 0.630 & 0.035 & 0.571 & 0.681 \\
\hline Justifiability of Dec. $\leftrightarrow$ MMCI & 0.328 & 0.052 & 0.240 & 0.415 \\
\hline
\end{tabular}

Leg. legitimacy, Dec. decision, $M M C I$ multimedia consumption intention

should normally be considered normal (status quo) is poorly evaluated during a crisis period. This paper advances the knowledge on norm theory, as it argues that in a sports context and during a crisis period, evaluations made by individuals 


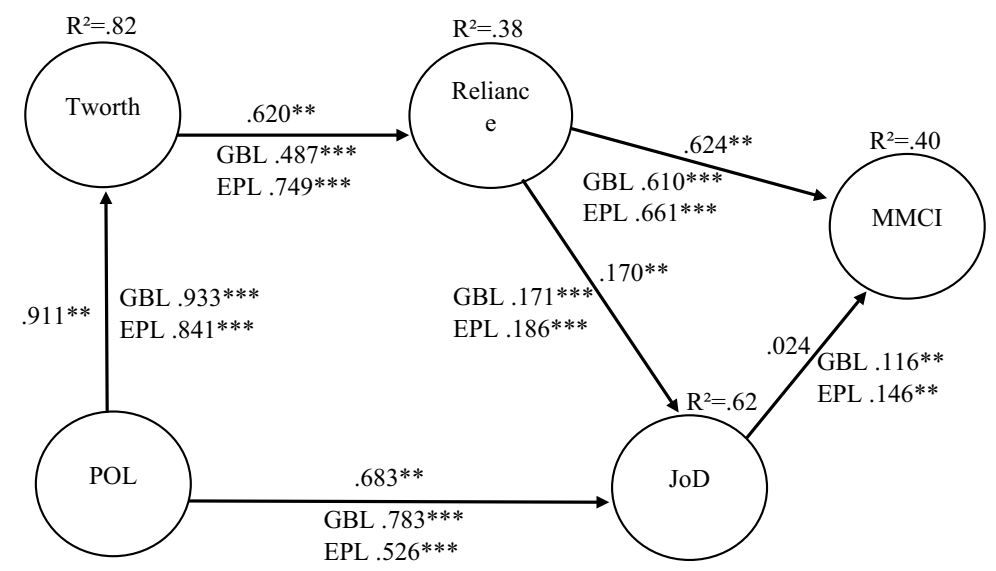

Fig. 2 Structural Equation Model Examining the Relationships among Perceived Organizational Legitimacy, Trustworthiness, Reliance, Justifiability of Decision and Multimedia Consumption Intention. Note: $* p<.10 * * p<.05 * * * p<.01$. Tworth=Trustworthiness, POL= Perceived Organizational Legitimacy, $\mathrm{JoD}=$ Justifiability of Decision, MMCI = Multimedia Consumption Intention. Moderation probability: $\mathrm{POL} \rightarrow$ Tworth .268, POL $\rightarrow \mathrm{JoD} .000^{* * *}$, Tworth $\rightarrow$ Reliance $.001^{* * *}$, Reliance $\rightarrow$ Jod .000***, Reliance $\rightarrow$ MMCI .202, JoD $\rightarrow$ MMCI .095*

Table 5 Multi-sample analysis - action (Bundesliga) versus inaction (Premier League)

\begin{tabular}{lllll}
\hline Constraint & $\begin{array}{l}\text { Estimated coeffi- } \\
\text { cient (Bundesliga) }\end{array}$ & $\begin{array}{l}\text { Estimated coefficient } \\
\text { (Premier League) }\end{array}$ & (d.f) $X^{2}$ differences & Probability \\
\hline $\mathrm{POL} \rightarrow$ Tworth & $.933^{* * *}$ & $.841^{* * *}$ & (1) 1.227 & .268 \\
$\mathrm{POL} \rightarrow \mathrm{JoD}$ & $.783^{* * *}$ & $.526^{* * *}$ & (1) 23.584 & $.000^{* * *}$ \\
Tworth $\rightarrow$ Reliance & $.487^{* * *}$ & $.749^{* * *}$ & (1) 10.540 & $.001^{* * *}$ \\
Reliance $\rightarrow$ JoD & $.171^{* * *}$ & $.186^{* * *}$ & (1) 36.546 & $.000^{* * *}$ \\
Reliance $\rightarrow$ MMCI & $.610^{* * *}$ & $.661^{* * *}$ & (1) 1.624 & .202 \\
$\mathrm{JoD} \rightarrow \mathrm{MMCI}$ & $.116^{* *}$ & $.146^{* *}$ & (1) 2.795 & $.095^{*}$ \\
\hline
\end{tabular}

$P O L$ perceived organizational legitimacy, Tworth trustworthiness, JoD justifiability of decision, $M M C I$ multimedia consumption intention

$* p<.10 * * p<.05 * * * p<.01$

are reversed to those expected during "normal" periods. Specifically, the fact that EPL did not intervene in salary agreements (downward) was perceived as acting the wrong way by doing nothing. Conversely, the GBL that actively worked on salary reductions (not normal) was perceived as positive actors, ultimately enjoying higher levels of consumption intention.

Decisions taken by trusted institutions appear as easier to justify; simultaneously, both reliance and justifiability derive into higher intentions to consume multimedia products from the sport leagues. This may be the case if fans evaluate a lack of action by the league as jeopardizing the continuity (Rousseau et al. 
1998) of the sports activity, representing higher risk of losing this entertainment source in a vulnerable time. These findings suggest that fans' judgments and evaluations would stick to a legitimacy baseline but simultaneously demand rapid adaptation to circumstances. Specifically, the fact that perceived organizational legitimacy toward trustworthiness shows no significant difference between the evaluated leagues argues that legitimacy is a baseline evaluation tool for fans regardless of the circumstances. However, after the confirmation of the invariance test, our findings suggest that Perceived Organizational Legitimacy $\rightarrow$ Justifiability of Decision, Trustworthiness $\rightarrow$ Reliance, Reliance $\rightarrow$ Justifiability of Decision, and Justifiability of Decision $\rightarrow$ Multimedia Consumption Intention strings are indeed significant. These findings indicate that specific contextual decisions are impacted by a more dynamic evaluation process made by the fans, which in turn would mean that, in a "new normality" context, international broadcasting audiences could tend to favor sport leagues who make quick adjustments and show an adaptation interest.

From a strategic management perspective, these findings argue that fans are sensible to actions taken during crisis periods, and attention toward fans' evaluation demands may be crucial. This is a relevant finding. For example, clubs are struggling with the lack of gate receipts, which represents the best way to attract sponsors, sign broadcasting contracts, and deliver their exposure to fans. It also argues that regardless of the situation or context, legitimacy is a foundation block for fans' judgment and a powerful tool for sport institutions that could be used/encouraged through communication strategies.

This study has a limitation in that it only considers two top leagues of a specific sport. Although football is a globally recognized sport, the limitation of this singlesport analysis should be considered when interpreting the findings. Although practical and efficient for data collecting, the fact that most of our research responses were obtained through Amazon's MTurk should arise as a tentative limitation (Aguinis et al. 2021). Nevertheless, due to the health crisis of the pandemic, it represented an optimal data collection option for the current investigation. Finally, readers should consider that the sample consists of international fans, therefore not all results are transferable to domestic fans. Proximity to the source and localness bias could affect the impact on fans and therefore additional research should be done to this type of consumers. Future research should consider the analysis of different sports or less relevant leagues, where localness or a preconceived smaller resource availability could arouse different responses. Therefore, replication of this research is recommended for different sport scenarios and nationalities.

Funding Funding for open access charge: Universidad de Granada / CBUA.

\section{Declarations}

Conflict of interest No potential conflict of interest was reported by the authors.

Open Access This article is licensed under a Creative Commons Attribution 4.0 International License, which permits use, sharing, adaptation, distribution and reproduction in any medium or format, as long as 
you give appropriate credit to the original author(s) and the source, provide a link to the Creative Commons licence, and indicate if changes were made. The images or other third party material in this article are included in the article's Creative Commons licence, unless indicated otherwise in a credit line to the material. If material is not included in the article's Creative Commons licence and your intended use is not permitted by statutory regulation or exceeds the permitted use, you will need to obtain permission directly from the copyright holder. To view a copy of this licence, visit http://creativecommons.org/licen ses/by/4.0/.

\section{References}

Aguinis H, Villamor I, Ramani RS (2021) MTurk research: review and recommendations. J Manag 47(4):823-837

Ajadi T, Burton Z, Dwyer M, Hammond T, Ross C (2020) 'Eye on the prize', Football Money League. Deloitte Sport Business Group, Manchester, pp 1-56. https://www2.deloitte.com/content/dam/ Deloitte/uk/Documents/sports-business-group/deloitte-uk-deloitte-football-money-league-2020.pdf. Accessed 13 July 2020

Alonso FM (2016) Reasons for reliance. Ethics 126(2):311-338

Anderson JC, Gerbing DW (1988) Structural equation modeling in practice: a review and recommended two-step approach. Psychol Bull 103(3):411-423

Bejou D, Ennew CT, Palmer A (1998) Trust, ethics and relationship satisfaction. Int J Bank Mark 16(4):170-175

Bellucci G, Park SQ (2020) Honesty biases trustworthiness impressions. J Exp Psychol Gen 149(8):1567-1586

Bertran A (2020) Claro Sports to broadcast the Bundesliga in Latin America. Nextv News International, pp 1-2. https://nextvnews.com/claro-sports-to-broadcast-the-bundesliga-in-latin-america-2/

Bitektine A (2011) Toward a theory of social judgments of organizations: the case of legitimacy, reputation, and status. Acad Manag Rev 36(1):151-179

Blay AD, Gooden ES, Mellon MJ, Stevens DE (2018) The usefulness of social norm theory in empirical business ethics research: a review and suggestions for future research. J Bus Ethics 152(1):191-206

Brehmer A, Brehmer B (1988) What have we learned about human judgment from thirty years of policy capturing? In: Stelmach GE, Vroon PA (eds) Advances in psychology. North-Holland, New York, pp 75-114

Caldwell C, Clapham SE (2003) Organizational trustworthiness: an international perspective. J Bus Ethics 47(4):349-364

Caldwell C, Hayes LA (2007) Leadership, trustworthiness, and the mediating lens. J Manag Dev 26(3):261-281

Chapman DW, Carter JF (1979) Translation procedures for the cross cultural use of measurement instruments. Educ Eval Policy Anal 1(3):71-76

Cheung GW, Rensvold RB (2009) Structural equation modeling : a evaluating goodness-of-fit indexes for testing measurement invariance. Struct Equ Model: Multi J 9(2):233-255

Cho S, Park C, Lee F (2020) Homophily and peerconsumer behaviour in a peer-to-peer accommodation sharing economy platform. Behav Inf Technol. https://doi.org/10.1080/0144929X.2020.1803403

Clark C, Davila A, Regis M, Kraus S (2020) Predictors of COVID-19 voluntary compliance behaviors: an international investigation. Glob Transit 2:76-82

Cobbs J, Hylton M (2012) Facilitating sponsorship channels in the business model of motorsports. J Mark Channels 19(3):173-192

Corsini A, Bisciotti GN, Eirale C, Volpi P (2020) Football cannot restart soon during the COVID-19 emergency! A critical perspective from the Italian experience and a call for action. Br J Sports Med $54: 1186-1187$

Crane B (2020) Revisiting who, when, and why stakeholders matter: trust and stakeholder connectedness. Bus Soc 59(2):263-286

Crocker L, Algina J (1986) Introduction to validity. Introduction to classical and modern test theory. Holt, Rinehart, and Winston, Fort Worth 
Dabbous A, Tarhini A (2019) Assessing the impact of knowledge and perceived economic benefits on sustainable consumption through the sharing economy: a sociotechnical approach. Technol Forecast Soc Change 149:119775

Das S (2021) Top 10 most popular sports in the world. Sports Show, pp 5-26. https://sportsshow.net/top10-most-popular-sports-in-the-world/. Accessed 13 Aug 2021

Doney PM, Cannon JP (1997) An examination of the nature of trust in buyer-seller relationships. J Mark 61(2):35-51

Drewes M, Daumann F, Follert F (2021) Exploring the sports economic impact of COVID-19 on professional soccer. Soccer Soc 22(1-2):125-137

Emami A, Ashourizadeh S, Sheikhi S, Rexhepi G (2021) Entrepreneurial propensity for market analysis in the time of COVID-19: benefits from individual entrepreneurial orientation and opportunity confidence. Rev Manag Sci. https://doi.org/10.1007/s11846-021-00499-0

Fan N, Wu CQ (2019) On trust models for communication security in vehicular ad-hoc networks. Ad Hoc Netw 90:101740. https://doi.org/10.1016/j.adhoc.2018.08.010

Feldman G (2020) What is normal? Dimensions of action-inaction normality and their impact on regret in the action-effect. Cogn Emot 34(4):728-742

Feldman G, Kutscher L, Yay T (2020) Omission and commission in judgment and decision making: understanding and linking action-inaction effects using the concept of normality. Soc Personal Psychol Compass 14:e12557

Fidan T, Balci A (2018) School administrators as legitimation agents: linking perceived organizational legitimacy and legitimation strategies. Educ Sci Theory Pract 18(2):253-277

Flores F, Solomon RC (1998) Creating trust. Bus Ethics Q 8(2):205-232

Fornell C, Larcker DF (1981) Evaluating structural equation models with unobservable variables and measurement error. J Mark Res 18(1):39-50

French BF, Finch WH (2006) Confirmatory factor analytic procedures for the determination of measurement invariance. Struct Equ Model 13(3):378-402

Garbarino E, Johnson MS (1999) The different roles of satisfaction, trust, and commitment in customer relationships. J Mark 63(2):70-87

Geey D, Harvey A (2019) Football broadcasting deals across the top 5 european leagues. Daniel Geey, pp 1-3. https://www.danielgeey.com/post/football-broadcasting-deals-across-the-top-5-european-leagu es/. Accessed 18 Aug 2021

Giulianotti R, Robertson R (2012) Mapping the global football field: a sociological model of transnational forces within the world game. Br J Sociol 63(2):216-240

Hammerschmidt J, Eggers F, Kraus S, Jones P, Filser M (2020) Entrepreneurial orientation in sports entrepreneurship: a mixed methods analysis of professional soccer clubs in the German-speaking countries. Int Entrep. Manag J 16(3):839-857. https://doi.org/10.1007/s11365-019-00594-5

Hammerschmidt J, Durst S, Kraus S, Puumalainen K (2021a) Professional football clubs and empirical evidence from the COVID-19 crisis: time for sport entrepreneurship? Technol Forecast Soc Change 165:120572. https://doi.org/10.1016/j.techfore.2021.120572

Hammerschmidt J, Kraus S, Jones P (2021b) Sport entrepreneurship: definition and conceptualization. J Small Bus Strategy (in press)

Haynes J (2021) The protection of sports broadcast rights in the commonwealth Caribbean after TVJ v CVM. Entertain Sports Law J 19(2):1-19

Hoffmann JA, von Helversen B, Rieskamp J (2019) Testing learning mechanisms of rule-based judgment. Decision 6(4):305-334

Horky T (2021) No sports, no spectators-no media, no money? The importance of spectators and broadcasting for professional sports during COVID-19. Soccer Soc 22(1-2):96-102

Hosmer LT (1995) Trust: the connecting link between organizational theory and philosophical ethics. Acad Manag Rev 20(2):379-403

Hutchins J, Sinha M, Nandan S (2019) The sustainability route to corporate legitimacy. J Glob Sch Mark Sci 29(1):15-24

Inman JJ, Zeelenberg M (2002) Regret in repeat purchase versus switching decisions: the attenuating role of decision justifiability. J Consum Res 29(1):116-128

Ismagilova E, Slade E, Rana NP, Dwivedi YK (2020) The effect of characteristics of source credibility on consumer behaviour: a meta-analysis. J Retail Consum Serv 53:101736

Jacobsen CB, Andersen LB (2015) Is leadership in the eye of the beholder? A study of intended and perceived leadership practices and organizational performance. Public Adm Rev 75(6):829-841. https://doi.org/10.1111/puar.12380 
Jöreskog KG (1971) Statistical analysis of sets of congeneric tests. Psychometrika 36(2):109-133

Kahneman D, Miller DT (1986) Norm theory: comparing reality to its alternatives. Psychol Rev 93(2):136-153

Kennedy D, Kennedy P (2021) English premier league football clubs during the covid-19 pandemic: business as usual? Soccer Soc 22(1-2):27-34

Kim YK, Trail G, Ko YJ (2011) The influence of relationship quality on sport consumption behaviors: an empirical examination of the relationship quality framework. J Sport Manag 25(6):576-592

Kim W, Kim N, Lyons JB, Nam CS (2020) Factors affecting trust in high-vulnerability human-robot interaction contexts: a structural equation modelling approach. Appl Ergon 85:103056

Knobloch-Westerwick S, Abdallah JC, Billings AC (2020) The football boost? Testing three models on impacts on sports spectators' self-esteem. Commun Sport 8(2):236-261

Kraus S, Clauss T, Breier M, Gast J, Zardini A, Tiberius V (2020) The economics of COVID-19: initial empirical evidence on how family firms in five European countries cope with the corona crisis. Int $\mathrm{J}$ Entrep Behav Res 26(5):1067-1092

Kyle G, Graefe A, Manning R, Bacon J (2004) Effects of place attachment on users' perceptions of social and environmental conditions in a natural setting. J Environ Psychol 24(2):213-225

Lovell G (2009) Can I trust you? An exploration of the role of trust in hospitality service settings. Tour Hosp Plan Dev 6(2):145-157

Majumdar B, Naha S (2020) Live sport during the COVID-19 crisis: fans as creative broadcasters. Sport Soc 23(7):1091-1099

Mandler T, Bartsch F, Han CM (2020) Brand credibility and marketplace globalization: the role of perceived brand globalness and localness. J Int Bus Stud 52:1559-1590

Mann RH, Clift BC, Boykoff J, Bekker S (2020) Athletes as community; Athletes in community: Covid19, sporting mega-events and athlete health protection. Br J Sports Med 54:1071-1072

Mao Q, Zhang M, Ma B (2018) Benefit and risk perceptions of controversial facilities: a comparison between local officials and the public in China. Sustainability 10:1092

Martínez D, Alguacil M, Calabuig F (2020) Influence of brand image of a sports event on the recommendation of its participants. Sustainability 12:1-13

Mastromartino B, Ross WJ, Wear H, Naraine ML (2020) Thinking outside the "box": a discussion of sports fans, teams, and the environment in the context of COVID-19. Sport Soc 23(11):1707-1723

Maxwell AL, Lévesque M (2014) Trustworthiness: a critical ingredient for entrepreneurs seeking investors. Entrep Theory Pract 38(5):1057-1080

Mayer RC, Davis JH (1999) The effect of the performance appraisal system on trust for management: a field quasi-experiment. J Appl Psychol 84(1):123-136

Moloney K (2005) Trust and public relations: center and edge. Public Relat Rev 31(4):550-555

Morrow JL Jr, Hansen MH, Pearson AW (2004) The cognitive and affective antecedents of general trust within cooperative organizations. J Manag Issues 16(1):48-64

Navarro-Picado JF (2019) Sponsorship sales is not only a sport, but an institutional business as well: evidence from two professional football clubs in Latin-America. Estudios De Administración 26(2):82-100

Navarro-Picado JF, Torres-Moraga EI, González-Serrano MH (2020) How are fans teams' consumption behaviors impacted by their federations' innovativeness perceived organizational legitimacy. Sport Soc $1-20$

Niemi L, Kantola J (2018) Legitimated consumption: a socially embedded challenge for entrepreneurs' value creation. J Res Mark Entrep 20(2):214-228

Nunnally JC (1994) Psychometric theory 3E. Tata McGraw-Hill Education, New York

Ödlund A (2010) Pulling the same way? A multi-perspectivist study of crisis cooperation in government. J Contingencies Crisis Manag 18(2):96-107

Ozdemir S, Zhang S, Gupta S, Bebek G (2020) The effects of trust and peer influence on corporate brand: consumer relationships and consumer loyalty. J Bus Res 117:791-805

Palttala P, Vos M (2011) Testing a methodology to improve organizational learning about crisis communication by public organizations. J Commun Manag 15(4):314-331

Pena-Marin J, Wu R (2019) Disconfirming expectations: incorrect imprecise (vs. precise) estimates increase source trustworthiness and consumer loyalty. J Consum Psychol 29(4):623-641

Press (2019) Premiere League global audience on the rise. Premier League, pp 1-5. https://www.premi erleague.com/news/1280062. Accessed 13 Aug 2021

Press (2020) La Bundesliga se verá gratis por toda Sudamérica. FC Bayern, pp 1-4. https://fcbayern.com/ es/noticias/2020/09/la-bundesliga-se-vera-gratis-por-toda-sudamerica. Accessed 18 Aug 2021 
Rhine RJ, Severance LJ (1970) Ego-involvement, discrepancy, source credibility, and attitude change. J Pers Soc Psychol 16(2):175-190

Ridge PT (2017) From sport to spectacle: an archaeology of Latin American Soccer. Doctoral dissertation, Arizona State University

Roan D (2020) Premier League clubs in 'moral vacuum' and players should sacrifice salary: politicians. BBC Sports, pp 1-7. https://www.bbc.com/sport/football/52120578. Accessed 13 Aug 2021

Rousseau DM, Sitkin SB, Burt RS, Camerer C (1998) Not so different after all: a cross-discipline view of trust. Acad Manag Rev 23(3):393-404

Saine R, Nguyen CA, Besharat A, Trocchia PJ (2018) To stay or switch: breaking the habit of status quo through imagery perspective. Eur J Mark 52(9-10):1864-1885

Sekhon H, Ennew C, Kharouf H, Devlin J (2014) Trustworthiness and trust: influences and implications. J Mark Manag 30(3-4):409-430

Sen S, Morwitz VG (1996) Consumer reactions to a provider's position on social issues: the effect of varying frames of reference. J Consum Psychol 5(1):27-48

Sheptak RD, Menaker BE (2020) When sport event work stopped: exposure of sport event labor precarity by the COVID-19 pandemic. Int J Sport Commun 13(3):427-435

Silva A, Monteiro D, Sobreiro P (2019) Effects of sports participation and the perceived value of elite sport on subjective well-being. Sport Soc 23(7):1202-1216

Smith KW (1974) On estimating the reliability of composite indexes through factor analysis. Sociol Methods Res 2:485-510

Sotomayor A (2020) Sport in Latin America and the Caribbean. Oxford bibliographies online. Oxford University Press, Oxford

Steenkamp JBEM, Geyskens I (2006) How country characteristics affect the perceived value of web sites. J Mark 70(3):136-150

Tamir I (2019) Digital video recorder dodgers-sport-viewing habits in the face of changing media reality. Time Soc 28(4):1319-1332

Temerak MS, El-Manstrly D (2019) The influence of goal attainment and switching costs on customers' staying intentions. J Retail Consum Serv 51(March):51-61

Van de Calseyde PPFM, Zeelenberg M, Evers ERK (2018) The impact of doubt on the experience of regret. Organ Behav Hum Decis Process 149:97-110

Van Swol LM, Braun MT, Acosta Lewis EE, Carlson CL, Dimperio G (2018) Discussion of shared information can increase the influence of divergent members. Commun Res 45(2):188-212

Verbruggen M, Van Emmerik H (2020) When staying is dissatisfying: examining when and why turnover cognitions affect stayers carrer satisfaction. J Manag 46(4):530-559

Zacharakis AL, Meyer GD (1998) A lack of insight: do venture capitalists really understand their own decision process? J Bus Ventur 13(1):57-76

Publisher's Note Springer Nature remains neutral with regard to jurisdictional claims in published maps and institutional affiliations. 